\title{
SUPERVISI KEPERAWATAN DI RUMAH SAKIT
}

\author{
Angga Satria Pratama ${ }^{1}$, Ardita Ayu Lestari², Kurniawan Yudianto ${ }^{3}$, \\ Sri Wulan Megawati ${ }^{4}$, Andria Pragholapati ${ }^{5}$ \\ 1,2,4) Universitas Bhakti Kencana \\ ${ }^{3)}$ Universitas Padjadjaran \\ 5) Universitas Pendidikan Indonesia \\ angga.satria@bku.ac.id
}

\begin{abstract}
ABSTRAK
Supervisi Keperawatan dapat memengaruhi kondisi perawat dalam membangkitkan, mengarahkan, dan memelihara perilaku yang berhubungan dengan lingkungan kerja perawat. Namun, kenyataannya pelaksanaan supervisi belum optimal. Tujuan penelitian ini untuk mengidentifikasi pelaksanaan supervisi keperawatan di ruang rawat inap RSUD Majalaya. Jenis penelitian menggunakan survei analitik. Metode pengambilan sampel menggunakan total sampling dengan jumlah sampel sebanyak 55 perawat pelaksanan di 6 ruang rawat inap. Teknik pengumpulan data mengggunakan kuesioner Manchester Clinical Supervision Scale 26-item (MCSS-26). Hasil penelitian menunjukkan 29 orang $(52,7 \%)$ mempersepsikan pelaksanaan supervisi keperawatan tidak baik. Berdasarkan hasil penelitian diharapkan adanya evaluasi atau program dalam upaya menyusun suatu kebijakan dan standar operasional terkait dengan kegiatan supervisi keperawatan yang dilakukan di ruangan khususnya rawat inap.
\end{abstract}

Kata kunci : perawat, rawat inap, supervisi keperawatan

\section{Abstract}

Nursing supervision can affect nurses' conditions in arousing, directing, and maintaining behaviour related to the nurse's work environment. However, in reality, the implementation of supervision is not yet optimal. The purpose of this study was to identify the implementation of nursing supervision in the inpatient room of Majalaya Regional Hospital. This type of research uses analytic surveys. The sampling method uses total sampling with a total sample of 55 nurses implementing in 6 inpatient rooms. Data collection techniques used the Manchester Clinical Supervision Scale 26-item (MCSS-26) questionnaire. The results showed that 29 people (52.7\%) perceived the implementation of nursing supervision was not good. Based on the results of the study it is expected that there is an evaluation or program to compile an international policy and standards related to nursing supervision activities carried out in the room, especially inpatients.

Keywords: inpatient, nurse, nursing supervision 


\section{PENDAHULUAN}

Keperawatan adalah bentuk pelayanan profesional yang menjadi bagian integral dari pelayanan kesehatan, didasarkan pada ilmu dan kiat keperawatan. Pelayanan yang diberikan berbentuk pelayanan bio-psiko-sosial-spiritual yang komprehensif, ditujukan kepada individu, keluarga, dan masyarakat, baik sehat maupun sakit yang mencakup seluruh proses kehidupan manusia. Dalam hal ini, keperawatan termasuk ke dalam organisasi pelayanan kesehatan, yang tentunya senantiasa terlibat dalam penerapan manajemen dan pencapaian tujuan keperawatan (Simamora, 2012)

Manajemen keperawatan mempunyai lingkup manajemen operasional yang merencanakan, mengatur, dan menggerakan para perawat untuk memberikan pelayanan keperawatan yang sebaik-baiknya kepada pasien melalui manajemen asuhan keperawatan. Agar manajemen yang dilakukan mengarah kepada kegiatan keperawatan secara efektif dan efisien, manajemen dalam keperawatan perlu dijelaskan berdasarkan fungsi-fungsi manajemen (managerial functions). Fungsi tersebut mencakup perencanaan, pengorganisasian, pengimplementasian, serta pengendalian dan pengawasan (Simamora, 2012).

Data yang diperoleh BPPSDMK (Badan Pengembangan dan Pemberdayaan Sumber Daya Manusia Kesehatan) per Desember 2016, proporsi jumlah perawat di antara SDM (Sumber Daya Manusia) kesehatan lainnya yang didayagunakan di fasilitas layanan kesehatan sebanyak 601.228 orang di antaranya adalah 6 tenaga kesehatan medis (dokter umum, dokter spesialis, dan dokter gigi), paramedis (bidan dan perawat), dan tenaga farmasi. Dari 6 tenaga kesehatan tersebut jumlah tenaga perawat adalah yang terbesar mencapai 49\% (296.876 orang). Rekapitulasi jumlah tenaga keperawatan dari total 296.876 orang perawat di Indonesia, jumlah perawat terbanyak di Provinsi
Jawa Tengah 35.773 orang, Jawa Barat 33.527 orang, dan Jawa Timur 33.377 orang tenaga keperawatan (BPSDMK, 2018).

Perawat adalah individu yang mempunyai profesi berdasarkan pengetahuan ilmiah, keterampilan serta sikap kerja yang dilandasi oleh rasa tanggung jawab dan pengabdian memberikan pelayanan asuhan keperawatan kepada klien dalam bentuk pelayanan professional yang bertujuan membantu pasien untuk memulihkan dan meningkatkan kemampuan dirinya. Pelayanan keperawatan di ruang rawat terdiri atas serangkaian kegiatan yang dikoordinasi oleh kepala ruang rawat dan menjadi tanggung jawab sebagai manajer (Simamora, 2012).

Manajer terus-menerus ditantang untuk memotivasi tenaga kerja dalam melakukan dua hal, yaitu: 1) Memotivasi karyawan untuk bekerja guna membantu organisasi mencapai tujuannya. 2) Memotivasi karyawan untuk bekerja demi mencapai tujuan pribadi mereka. Dalam pelayanan kesehatan, pemenuhan kebutuhan dan pencapaian tujuan baik atasan maupun bawahan seringkali lebih sulit dicapai. Agar berhasil, manajer layanan kesehatan harus mampu mengelola dan memotivasi berbagai jenis karyawan (Buchbinder, 2014).

Supervisi keperawatan merupakan suatu bentuk dari kegiatan manajemen keperawatan yang bertujuan dalam pemenuhan dan peningkatan pelayanan untuk klien dan keluarga yang berfokus pada kebutuhan, keterampilan, dan kemampuan perawat dalam melaksanakan tugas (Nursalam, 2015). Hal ini dibuktikan dengan penelitian dari (Patintingan, Pasinringi, \& Anggraeni, n.d.) Gambaran Motivasi Kerja Perawat Di Ruang Rawat Inap Rumah Sakit Universitas Hasanuddin Makasar. Diperoleh data bahwa motivasi kerja perawat rawat inap RS Unhas, terkait dengan supervisi memiliki presentase (83.1\%). Penelitian terebut menunjukkan bahwa dengan diadakannya supervisi pimpinan maka perawat termotivasi 
untuk meningkatkan kinerja mereka.

Pelaksana supervisi keperawatan dapat dilakukan oleh pemangku jabatan dalam berbagai level, seperti; ketua tim, kepala ruangan, perawat pengawas, kepalaseksi,kepalabidangkeperawatan ataupun wakil direktur keperawatan. Kegiatan pokok pada dasarnya supervisi mencakup empat hal, yaitu 1) menetapkan masalah dan prioritas; 2) menetapkan penyebab masalah, prioritas, dan jalan keluar; 3) melaksanakan jalan keluar; 4) menilai hasil yang dicapai untuk tindak lanjut berikutnya. Pelaksanaan supervisi yang baik dilakukan dengan dua teknik, dimana dilakukan secara langsung dan tidak langsung (Nursalam, 2015).

Rumah Sakit Umum Daerah Majalaya adalah RSUD milik pemerintah Daerah Kabupaten Bandung, awalnya adalah Puskesmas yang dibangun tahun 1951 dan mulai dipergunakan tahun 1955, karena perkembangannya pada tanggal 2 Juni 2010 telah ditetapkan menjadi Rumah Sakit Umum Daerah Tipe "B" (MENKES 2010). Rumah Sakit ini mempunyai visi dan misi dalam mewujudkan dan meningkatkan pelayanan kesehatan prima yang mandiri dan berwawasan pendidikan (RSUD Majalaya, 2017).

Data yang didapat dari RSUD Majalaya Kabupaten Bandung bahwa keseluruhan jumlah perawat yang bekerja 233 orang, sedangkan jumlah perawat rawat inap 152 orang dan 10 bidan, dimana memiliki 13 ruang rawat inap yaitu Ruang Aster (10 perawat), Ruang Cempaka (11 perawat), Ruang Teratai (15 perawat), Ruang Teratai HCU (11 perawat), Ruang Dahlia (17 perawat), Ruang Kenanga (10 perawat), Ruang ICU (14 perawat), Ruang Melati (10 perawat), Ruang Anggrek VIP (10 perawat), Ruang Anyelir I (14 perawat), Ruang Anyelir II (14 perawat), Ruang Flamboyan (16 perawat) dan Ruang Mawar/Nifas (10 bidan) (Pragholapati, 2020).

Berdasarkan studi pendahuluan pada tanggal 3 April 2018 didapatkan hasil wawancara yang dilakukan peneliti terhadap kepala bidang keperawatan RSUD Majalaya Kabupaten Bandung, pelaksanaan supervisi yang ada di RSUD Majalaya dibagi menjadi dua, yaitu ; supevisi manajerial, dimana pelaksanaannya rutin dilakukan setiap hari dengan waktu sesuai jam shif kerja (pagi, sore, malam).

Supervisi yang dilakukan berupa mengawasi, mengobservasi, mengevaluasi, memberikan solusi dan juga memotivasi keja terhadap tenaga kesehatan, seluruh pelayanan rumah sakit, sarana dan pasarana rumah sakit secara menyeluruh yang dilakukan oleh pengawas (supervisor/MOD (Manager On Duty)). Sedangkan supervisi klinik/keperawatan dilakukan berjenjang yaitu 3 bulan sekali yang mulai pelaksanaannya sejak awal tahun 2018, standar operasional prosedur (SOP) pelaksanaan supervisi keperawatan yang belum ada, karena memang masih dalam rancangan pembuatan. Dalam pelaksanaannya dilakukan oleh pengawas keperawatan/kepala ruangan/ketua tim. Menurut kepala ruangan yang ada di salah satu ruangan rawat inap, mengatakan bahwa pelaksanaan supervisi memang belum optimal, seperti: frekuensi pelaksanaan yang belum teratur, bahan yang disupervisi belum jelas, dan supervisi yang dilakukan baru hanya sebatas mengamati serta mencatat yang dilakukan secara tidak langsung. Adapun motivasi perawat ruangan di ruang rawat inap RSUD Majalaya masih belum baik, hal tersebut dapat mempengaruhi kualitas kinerja dan kepuasan pelayanaan keperawatan, bisa ditunjukkan dengan ekspresi muka yang kurang ramahterhadappasiendan keluarga,meninggalkan ruangan saat jam kerja, pendokumentasian yang tidak lengkap, dan, masih ada perawat datang terlambat. Berdasarkan hasil wawancara dengan 8 perawat pelaksana di ruang rawat inap, 6 orang dari perawat tersebut mengatakan bahwa merasa jenuh dengan pekerjaanya serta tidak punya gairah untuk bekerja, dalam melaksanakan 
pelayanan keperawatan sering tidak sesuai dengan SOP dikarenakan peralatan yang tidak memadai, ketidakadilan dalam mendapatkan tunjangan penambahan penghasilan sedangkan tenaga kesehatan lain mendapatkannya. Selain itu peneliti juga menemukan 4 orang dari 8 perawat tersebut mengatakan bahwa suasana di tempat kerjanya sudah tidak kondusif antara perawat dikarenakan adanya rasa saing ingin mendapatkan pengakuan dan kenaikan jabatan, kurangnya pengawasan dari pimpinan khususnya pengawas keperawatan sehingga perawat tersebut merasa tidak diperhatikan dengan melakukan hal yang benar pun tidak ada penghargaan (reawed) dan ketika melakukan kesalahanpun tidak ada teguran.

Hasil wawancara dengan ketua komisariat RSUD Majalaya bahwa pelatihan untuk perawat rawat inap yang dikhususkan itu belum terencana dan belum pernah diadakan, hanya saja RS sudah mempunyai program pelatihan BHD yang diperuntukan untuk semua karyawan petugas tenaga medis. Adapun pelatihan BTCLS, EKG itu hanya diperuntukan dan di wajibkan untuk ruanganruangan tertentu, seperti; IGD, ICU, OK, dan HD. Sedikitnya pelatihan untuk tenaga perawat rawat inap mengakibatkan harapan perawat terhadap pekerjaannya kurang.

Berdasarkan fenomena tersebut pengetahuan manajemen keperawatan dan kemampuan kepemimpinan sangat diperlukan oleh seorang pelaksana yang bertanggung jawab dalam melakukan pengawasan (supervisor/ supervisi) keperawatan agar dapat melaksanakan supervisi secara optimal dalam upaya meningkatkan motiasi kerja perawat, sehingga penerapan pelayanan keperawatan akan lebih bermutu dan profesional. Maka peneliti tertarik untuk meneliti tentang "Gambaran pelaksanaan supervisi keperawatan di ruang rawat inap RSUD Majalaya Kabupaten Bandung Tahun 2018”.

\section{METODOLOGI}

Populasi dalam penelitian ini adalah perawat pelaksana di ruang rawat inap kelas I, II, dan III RSUD Majalaya yang terdiri dari 6 ruang rawat inap (Ruang Aster, Flamboyan, Dahlia, Kenanga, Melati dan Anggrek) dengan jumlah 55 perawat pelaksana. Teknik sampling yang digunakan dalam penelitian ini adalah Total Sampling. Total Sampling adalah pengambilan sampel dimana seluruh populasi dijadikan sebagai sampel, sehingga sampel dalam penelitian ini berjumlah 55 PP (Perawat Pelaksana).

Kuesioner ini merupakan kuesioner untuk mengukur kualitas pelaksanaan supervisi keperawatan yang di persepsikan oleh perawat rawat inap dan menjadi responden dalam penelitian ini akan diukur dengan menggunakan kuesioner Manchester Clinical Supervison Scale 26item (MCSS-26) yang berisi 26 item pernyataan dan mempunyai gradasi penilaian berbentuk skala likert dengan empat poin (Sangat Tidak Setuju, Tidak Setuju, Setuju, Sangat Setuju). Setiap item MCSS-26 diberi skor antara 1 hingga 4 dan dengan demikian total skor keseluruhan dapat berkisar dari 1 hingga 104. Kuesioner ini didapatkan dari ("MCSS-26 - White Winstanley," n.d.) Indikator dalam kusioner ini meliputi komponen normatif, komponen formatif, dan komponen restoratif (Kumar, 2015). Uji validitas isi yaitu meminta pendapat atau masukan tentang isi instrumen atau kuesioner yang telah disusun atau yang telah ada kepada beberapa orang yang ahli dalam bidangnya. Pada validitas content kuesioner supervisi keperawatan yang sebelumnya di alih bahasakan kepada NEC (National English Center) oleh Mr. Arfian Hikmat Ramadan, S.Pd., M.Hum. Kuesioner ini dilakukan uji content validity oleh ahli keperawatan manajemen. Nilai uji validitas kuesioner supervisi keperawatan berkisar antara 0,362 sampai 0,644. Berdasarkan uji reliabilitas, 
diperoleh koefisien reliabilitas alpha chroanbach sebesar 0,923 diatas standar yang ditetapkan yaitu 0,7 .

Penelitian sudah mendapatkan

persetujuan Ethical Clearance oleh lembaga dengan nomor 010/Stikes BK/YAGK/LPPM.1/ VI/2018. Penelitian mengikuti prinsip etik penelitian yaitu, Respect for human dignity, respect for privacy and confidentiality, Respect for justice and inclusiveness, dan Blancing harms and benefits. Penelitian ini dilakukan di ruang rawat inap RSUD Majalaya. Penelitian ini dilaksanakan pada bulan Juni sampai dengan bulan Juli 2018.

HASIL

Data hasil penelitian terhadap 55 responden yang diantaranya adalah responden atau perawat pelaksana yang ada di 6 ruang rawat inap RSUD Majalaya Kabupaten Bandung pada tanggal 9 Juli sampai tanggal 12 Juli tahun 2018. Gambaran pelaksanaan supervisi keperawatan dihitung skor jawaban dari masingmasing responden dalam penelitian, sehingga dapat ditentukan kriteria mana yang termasuk pelaksanaan supervisi keperawatan yang baik dan tidak baik berdasarkan persepsi perawat dari 55 responden.

Tabel 1. Gambaran Disribusi Frekuensi

Pelaksanaan Supervisi Keperawatan

\begin{tabular}{lcc}
\hline Pelaksanaan Supervisi & f & \% \\
\hline Baik & 26 & 47,3 \\
Tidak baik & 29 & 52,7 \\
\hline Total & 55 & 100 \\
\hline
\end{tabular}

Berdasarkan tabel 1 didapatkan hasil

lebih dari setengah perawat pelaksana yaitu 29 orang $(52,7 \%)$ di ruang rawat inap RSUD Majalaya mempersepsikan bahwa pelaksanaan supervisi keperawatan tidak baik.

Tabel 2. Distribusi Frekuensi Aspek Supervisi Keperawatan

\begin{tabular}{lcccccc}
\hline \multirow{3}{*}{ Supervisi Keperawatan } & \multicolumn{6}{c}{ Aspek } \\
\cline { 2 - 8 } & \multicolumn{2}{c}{ Normatif } & \multicolumn{2}{c}{ Formatif } & \multicolumn{2}{c}{ Restoratif } \\
\cline { 2 - 7 } & f & \% & f & \% & f & \% \\
\hline Baik & 26 & 47,3 & 25 & 45,5 & 26 & 47,3 \\
Tidak Baik & 29 & 52,7 & 30 & 54,5 & 29 & 52,7 \\
\hline
\end{tabular}

Berdasarkan tabel 2 didapatkan hasil bahwa pelaksanaan supervisi keperawatan menurutperawatpelaksana, dari ketiga aspekpada aspek normatif dan restortatif hampir sebagian dari perawat pelaksana di ruang rawat inap RSUD Majalaya mempersepsikan bahwa pelaksanaan supervisi keperawatan baik yaitu masing-masing seimbang dengan 26 (47,3\%). Selanjutnya aspek formatif lebih dari setengah perawat pelaksana yaitu $30(54,5 \%)$ mempersepsikan pelaksanaan supervisi keperawatan tidak baik.

\section{PEMBAHASAN}

\section{Gambaran \\ Pelaksanaan \\ Supervisi Keperawatan}

Hasil penelitian didapatlebih dari setengah perawat pelaksana yang menjadi responden pada saat penelitian di ruang rawat inap RSUD Majalaya Kabupaten Bandung mempersepsikan pelaksanaan supervisi keperawatan tidak baik yaitu 29 perawat pelaksana $(52.7 \%)$ dan hamper sebagian dari perawat pelaksana mempersepsikan pelaksanaan supervisi keperawatan baik yaitu 26 (47.3\%). Hasil ini dapat dilihat pada tabel 1 Pelaksana atau yang bertanggung jawab melaksanakan supervisi adalah atasan, yakni mereka yang memiliki kelebihan dalam organisasi, kelebihan yang dimaksud dikaitkan dengan status yang lebih tinggi (supervisor) dan karena itu fungsi supervisi memang dimiliki oleh atasan. Namun untuk keberhasilan, supervisi harus lebih mengutamakan kelebihan pengetahuan dan 
keterampilan (Nursalam, 2015).

Berdasarkan tabel 1 lebih dari setengahnya perawat pelaksana mempersepsikan pelaksanaan supervisi keperawatan tidak baik yakni 29 perawat pelaksana (52.7\%). Hasil instrumen didapatkan dari 55 perawat pelaksana yang mempersepsikan pelaksanaan supervisi keperawatan tidak baik paling banyak ialah mensetujui pernyataan dimana perawat sulit mendapatkan waktu untuk melakukan kegiatan pengawasan klinis, kegiatan pengawasan klinis bersifat membosankan, dan atasan menunjukkan sikap berkuasa ketika melakukan pengawasan. Persepsi ini dikemukakan oleh perawat dari kemampuan supervisor untuk mempertahankan kinerja staf yang baik masih dianggap belum berjalan maksimal, supervisor masih belum mampu untuk membantu bawahan secara langsung sehingga dalam melaksanakan tugasnya perawat masih kurang efektif.

Tambun, Setiawan, \& Simamora (2020) menyatakan bahwa kegiatan supervisi di rumah sakit masih belum dapat dilakukan dengan baik dikarenakan ada kendala yaitu belum tersedianya formulir untuk pendokumentasian supervisi, belum adanya acuan atau pedoman dalam melakukan supervisi, dan juga belum tersedianya waktu khusus untuk melaksanakan supervisi. Waktu dalam melakukan supervisi menjadi kendala di rumah sakit (Snowdon et al., 2019).

Hasil penelitian Imelda (2015) yang menyatakan bahwa terdapat pengaruh supervisi kepala ruangan terhadap kelengkapan dokumentasi asuhan keperawatan, sehingga diharapkan kepala ruangan lebih memotivasi, memberikan dukungan, penghargaan, dan fasilitas agar perawat pelaksana dapat mendokumentasikan asuhan keperawatan kearah yang lebih baik dan sesuai dengan standar keperawatan.

Berdasarkan tabel 2 dapat diketahui hasil penelitian mengenai pelaksanaan supervisi keperawatan di ruang rawat inap RSUD Majalaya terlihat dari fungsi supervisi keperawatan pada komponen formatif yaitu (45.5\%) perawat pelaksana mempersepsikan pelaksanaan supervisi keperawatan baik, yang berarti lebih dari setengah perawat pelaksana (54.5\%) mempersesikan pelaksanaan supervisi keperawatan tidak baik. Hasil instrument yang paling banyak dari 55 perawat pelaksana mempersepsikan dari pernyataan bahwa supervisor masih belum mampu mengkoordinir dan mengorganisasikan perawat pelaksana.

Menurut, (Allen, McCartan, Diperoleh, \& 2010, n.d.), tugas dari seorang supervisor berfokus pada pengembangan pengetahuan dan keterampilan staf sehingga staf bekerja sesuai dengan standar yang berlaku sebagai aspek tanggung jawab dalam melakukan praktek. Supervisor dalam memberikan supervisi yang efektif dapat meningkatkan kinerja perawat, meningkatkan kepercayaan diri, memberikan kesempatan untuk merefleksikan praktik, dapat saling berbagi ide, dan membandingkan praktik yang telah dilakukan (Bradley, 2019; Schaffarzyk, 2018).

Hasil ini didukung dengan pernyataan instrument yang paling banyak adalah kurang berjalannya kemampuan supervisor dalam memberikan dorongan, dukungan, saran, dan pembelajaran kepada perawat pelaksana.

Allen, McCartan, \& McClymont (2010) menjelaskan bahwa fungsi dukungan dapat membantu staf yang disupervisi untuk meningkatkan peran staf dari waktu ke waktu. Hal ini terjadi pada situasi tertentu, kejadian khusus atau masalah pribadi yang dapat berdampak pada pekerjaan dan kinerja. Mencegah persepsi negatif yang mempengaruhi mereka dan pekerjaan mereka dengan pemberian dukungan dan kesempatan untuk mereflesikan peran staf mengenai pekerjaannya. Pendapat yang sama di ungkapkan (Pitman, n.d.), pemberian dukungan akan dicapai dengan cara menciptakan 
lingkungan yang aman pada saat supervisi dimana kerahasiaan dan kepercayaan dibuat untuk mengklarifikasi batas-batas antara dukungan dan konseling, dan memberikan kesempatan staf yang disupervisi untuk mengekspresikan perasaan dan ide-ide yang berhubungan dengan pekerjaan.

Hal seperti ini yang kerap kali terjadi, bahwa masih kurangnya perencanaan, pengarahan, bimbingan, motivasi, bahkan evaluasi yang dilakukan oleh supervisor sehingga pelaksanaan supervisi keperawatan dinilai masih kurang baik. Pelaksanaan supervisi keperawatan dapat berjalan baik apabila ditinjau juga dengan pemilihan supervisor yang dapat memotivasi dan menstimulasi perawat pelaksana. Hal tersebut didukung dengan penelitian Wirawan (2013) bahwa karakteristik individu merupakan komponen yang berdampak langsung dengan supervisi keperawatan dimana usia, jenis kelamin, masa kerja, dan pendidikan berhubungan positif tetapi berkekuatan lemah terhadap keselamatan klien. Penelitian Widiyanto (2017) menyebutkan bahwa kinerja perawat meningkat setelah disupervisi oleh tim supervisor yang terlatih, dimana supervisi yang benar akan meningkatkan kenyamanan dari staf sehingga staf dapat melaksanakan pelayanan keperawatan dengan baik.

\section{SIMPULAN DAN SARAN}

Lebih dari setengah perawat pelaksana mempersepsikan pelaksanaan supervisi keperawatan tidak baik di ruang rawat inap RSUD Majalaya Kabupaten Bandung. Pihak Rumah sakit perlu mengadakan evaluasi atau program dalam upaya menyusun suatu kebijakan dan standar operasional terkait dengan kegiatan supervisi keperawatan yang dilakukan di ruangan khususnya rawat inap, mampu memberikan pelatihan tentang manajemen keperawatan dan manajemen asuhan keperawatan bagi calon kepala ruangan dan ketua tim untuk meningkatkan kemampuan fungsi manajemen dan kemampuan dalam melakukan supervisi.

\section{DAFTAR PUSTAKA}

Allen, A., McCartan, P., Diperoleh, J. M.-L. N. L., \& 2010, undefined. (n.d.). Profesional/ clinical supervision handbook for allied health profesionals.

BPSDMK. (2018, Maret 19). Pusat data dan Informasi Kementrian Kesehatan. Retrieved from Kemenkes RI: http:// bppsdmk.kemkes.go.id,

Bradley, I. A. (2019). More Nurse Supervisors Wanted. Kai Tiaki Nursing New Zealand, 25(9), 34-35

Buchbinder. (2014). Buku Ajar Manajemen Pelayanan Kesehatan. Jakarta: EGC.

Kumar, S., Osborne, K., \& Lehmann, T. (2015) 'Clinical supervision of allied health professionals' in country South Australia: A mixed methods pilot study' Australian Journal of Rural Healt, 23(5):265-271.

MCSS-26 - White Winstanley. (n.d.). Retrieved June 1, 2020, from https://whitewinstanley. com/mcss $26 /$

Nursalam. (2015). Manajemen keperawatan aplikasi dalam praktik keperawatan. Jakarta: Salemba

Patintingan, Y. M., Pasinringi, S. A., \& Anggraeni, R. (n.d.). Gambaran Motivasi Kerja Perawat Di Ruang Rawat Inap Rumah Sakit Universitas Hasanuddin Makassar Description of Nurse Work Motivation At In-Patient of Hasanuddin University Hospital. In core. ac.uk. Retrieved from https://core.ac.uk/ download/pdf/25492068.pdf

Pitman, S. (n.d.). Handbook for Clinical Supervisors: Nursing Post-Graduate Programmes. In pdfs.semanticscholar.org. Retrieved from http://epubs.rcsi.ie/ilhmrep/2

Pragholapati, A. (2020). Motivasi Kerja Perawat Di Ruang Rawat Inap Rsud Majalaya 
Kabupaten Bandung. Retrieved from https://psyarxiv.com/xfng4/

Schaffarczyk, K. (2018). Clinical Supervision in a Large Teaching Hospital: The Dawn of a New Era. https://www.acn.edu.au/ nurseclick/clinical-supervision-in-alarge-teaching-hospital-the-dawn-of-anew-era\#comments

Simamora, R. (2012). Buku ajar manajemen keperawatan. Retrieved from http:// r 2 kn.litbang.kemkes.go.id:8 080 / handle/123456789/76568

Snowdon, D. A., Sargent, M., Williams, C. M., Maloney, S., Caspers, K., \& Taylor, N. F. (2019). Effective Clinical Supervision of Allied Health Professionals: A Mixed Methods Study. BMC Health Services Research, 20(1).https://doi.org/10.1186/ s12913-019-4873-8

Suarli, S., \& Bahtiar, Y. (2009). Manajemen keperawatan dengan pendekatan praktis. Retrieved from http:// r 2kn.litbang.kemkes.go.id:8080/ handle/123456789/61952

Tambun, Y., Setiawan, S., \& Simamora, R. (2020). Persepsi Perawat tentang Supervisi Klinis Pelaksanaan Edukasi Pasien dan Keluarga. Jurnal Keperawatan Silampari, 3(2), 607-617. https://doi.org/https://doi. org/10.31539/jks.v3i2.1121

Widiyanto, P., Hariyanti, S.T., \& Handiyani. (2017). Pengaruh Pelatihan Supervisi Terhadap Penerapan Supervisi Klinik Kepala Ruangan dan Peningkatan Kualitas Tindakkan Perawatan Luka Di RS PKU Muhammadiyah Temanggung. Jurnal Unimus.

Wirawan, A.W., Novitasari, D., \& Wijayanti, F. (2013). Hubungan Antara Sepervisi Kepala Ruangan Dengan Pendokumentasian Asuhan Keperawatan Di Rumah Sakit Umum Daerah Ambarawa. Jurnal Managemen Keperawatan.1(1): 1-6. 